\title{
Assessment of Hospital Nurses' Moral Intelligence: A Cross-Sectional Study in Guilan Province, North of Iran
}

\author{
Seyed Ali Majidi ${ }^{1,{ }^{*}}$, Sobhaneh Kouchakzadeh ${ }^{2}$, Hamideh Safarmohammadi $^{3}$ and Ehsan \\ Kazemnezhad Leyli ${ }^{4}$ \\ ${ }^{1}$ Associate Professor in Health Services Management, Department of Nursing and Midwifery, Rasht Branch, Islamic Azad University, Rasht, Iran \\ ${ }^{2}$ MS Nursing, Department of Nursing and Midwifery, Rasht Branch, Islamic Azad University, Rasht, Iran \\ ${ }^{3}$ BS Nursing, Poursina Education and Treatment Center, Guilan University of Medical Sciences, Rasht, Iran \\ ${ }^{4}$ Associate Professor in Biostatistics, Guilan Road Trauma Research center, Guilan University of Medical Sciences, Rasht, Iran \\ "Corresponding author: Associate Professor in Health Services Management, Department of Nursing and Midwifery, Rasht Branch, Islamic Azad University, Rasht, Iran. E-mail: \\ salimajidi@gmail.com
}

Received 2017 September 28; Revised 2018 July 19; Accepted 2018 August 01.

\begin{abstract}
Background: The emphasis placed on ethics and moral considerations has always been considered in individual and social domains, and moral intelligence is one of the important components that can play a key role in the improvement of nursing profession. In fact, among different professions, nursing is a clear indication of moral performance.

Objectives: The overriding aim of the present study was to evaluate the moral intelligence of nurses working in hospitals of Guilan Province, Iran.

Methods: This cross-sectional descriptive study was conducted among 200 nurses working in hospitals of Guilan Province. The participants were chosen using the two-stage cluster sampling method. Data were collected using Lennick and Kiel's moral intelligence scale, which is a standard and localized questionnaire. To analyze the data, Mann-Whitney and Kruskal Wallis tests were run in SPSS, version 16.

Results: The highest percentage of the respondents (65\%) had a moderate level of moral intelligence, and the least percentage of the subjects (4.5\%) had a low level of moral intelligence. Three moral competencies including "Admitting mistakes and failures" (15.46 \pm 0.093), "Keeping promises" (15.24 \pm 2.13$)$ and "Actively caring about others" (15.16 \pm 2.32$)$ achieved the maximum scores within the range of 4 to 20 . Were the most important competencies of moral intelligence, respectively. The Kruskal Wallis test reflected a significant difference in the comparative study of nurses' moral intelligence based on age, gender, department, and educational level $(\mathrm{P}<0.05)$.

Conclusions: The desirable level of moral intelligence in nurses indicates the importance of obtaining moral values and emphasizes the existence of moral values in the clinical environment. Attention to factors affecting moral intelligence plays an important role in improving nurse's clinical performance.
\end{abstract}

Keywords: Hospital, Moral Intelligence, Nurse

\section{Background}

The existential philosophy of health systems promotes the health of people and the society, which is only possible through providing the desired care. In this regard, the most important, common, and comprehensive center for providing this type of care is the hospital, and the patient is the main focus of care and the sole cause of the hospital's existence (1). Today, hospitals are increasingly involved in a problem called moral rage. In today's dynamic and high-risk world, managers and employees of hospitals must consider moral principles and moral intelligence for improving their survival (2).
The emphasis placed on ethics and moral considerations in individual and social domains has always been considered as one of the important scientific and philosophical issues (3). Observing moral principles such as honesty, accountability, and commitment to provide the best care possible is greatly influenced by moral standards. Nurses with these characteristics can establish good rapport and an appropriate relationship with patients (4).

Moral issues are among the primary concerns in daily nursing care, and nurses try to adhere to them in order to provide better and more basic care for patients (5). Another issue in this regard is the relationship that exists between moral practice and making appropriate and sound 
decisions regarding the importance of nursing responsibilities, as nurses must first act as an ethical factor for the purpose of ethics in practice (6). Overall, a nurse's personality is built on ethics and accountability, and moral responsibility for individual performance and judgment is at the center of the nursing profession. In fact, nurses who are engaged in activities that maintain moral integrity have a stronger sense of themselves and their actions and have confidence in choosing the right way to perform the correct and best practices (7).

Moral intelligence is one of the important components that can play a constructive role in improving nurses' occupational and psychological statuses. In fact, among different professions, nursing can be a clear indication of moral performance (8). The concept of moral intelligence was first introduced by Borba. From this researcher's point of view, moral intelligence refers to the potential and ability of an individual to distinguish between right and wrong and to have strong moral beliefs and act upon them $(9,10)$.

Moral intelligence acts as a guide for human behavior and helps human beings in clever and optimal actions. Lennick and Kiel stated that moral intelligence includes four major dimensions of honesty, responsibility, forgiveness, and compassion. Honesty means harmony between beliefs and actions of an individual, in effect, doing what we know is right and telling the truth at all times. Responsibility entails accepting actions and their consequences such as mistakes and failures. Forgiveness includes awareness of imperfections and mistakes and subsequently, forgiving oneself and others. Compassion denotes giving attention to others (11).

Furthermore, Lennick et al. acknowledged the fact that judgment of good and bad deeds is originated from universal principles and crosses all cultural barriers. They mentioned 10 competencies related to moral intelligence, such as acting consistently upon principles, values, and beliefs, telling the truth, standing up for what is right, and keeping promises (8). Martin et al. introduced moral intelligence as a profound belief in the doctrines and values that guide and direct all thoughts and activities of an individual (5).

Compliance with moral standards in the performance of nurses is more important than other critical care items. Compliance with ethical standards in nursing practice leads to the improvement of nursing services, and the enhancement of the quality of nursing care has a significant effect on improving the patient recovery process. In addition, the attention paid by the nurses to moral issues will increase their ability and productivity as far as possible (12, 13).

Despite the importance of moral intelligence in promoting the performance of nurses, no studies have yet been conducted on this issue in Guilan Province, Iran. In this study, we sought to evaluate the different dimensions of moral intelligence in nurses working in hospitals of Guilan Province. In general, improvement of moral capabilities of nurses could provide high quality services for patients.

\section{Objectives}

The purpose of this study was to evaluate the moral intelligence of nurses working in hospitals of Guilan Province. The research question was how is the moral intelligence score of nurses in general and in terms of its aspects.

\section{Methods}

We used the Lennik and Keil's moral intelligence questionnaire to collect data. The questionnaire consists of 40 items rated using a 5-point Likert scale (i.e., never, infrequently, sometimes, in most situations, and in all situations) (11).

The various competencies of the moral competency inventory (MCI) are as follows:

(1) Acting consistently with principles, values, and beliefs

(2) Telling the truth

(3) Standing up for what is right

(4) Keeping promises

(5) Taking responsibility for personal choices

(6) Admitting mistakes and failures

(7) Embracing responsibility for serving others

(8) Actively caring about others

(9) Ability to let go of one's own mistakes

(10) Ability to let go of others' mistakes

Reliability and validity of this questionnaire have been established in previous studies (14). In this study, the validity and reliability of this questionnaire were evaluated as well. To establish the validity of the scale in this study, the questionnaire was presented to 10 experts in the field of nursing (i.e., 5 Ph.D. graduates and 5 senior nursing staffs) who had experience in clinical nursing and research. To determine the content validity index (CVI), the experts were asked to rate each item based on relevance, clarity, simplicity using a Likert scale. In addition, to determine content validity ratio (CVR), each item was rated based on it is necessary, it is useful, but not necessary, and it is not necessary. CVI was calculated as $85 \%$ and CVR was found to be more than $90 \%$. Cronbach's alpha reliability of the questionnaire was calculated to be 0.88 . 
After estimating CVI and CVR, the final questionnaire was designed. After obtaining legal and ethical permissions in August 2016, the questionnaire was distributed among 200 nurses working all across Guilan Province during two months.

The study population comprised all nurses working in hospitals of Guilan Province and the study setting was hospital. The sampling method was the two-stage cluster sampling method. In the first stage, the list of cities, hospital departments and the staff working in them was prepared. Due to the large number of the employed nursing staff throughout the province's hospitals, 10 cities were randomly selected based on random numbers (this study was conducted in public hospitals). Considering the large number of active nurses in each city, 20 nurses were randomly selected from each cluster (in this study, each city was considered as a cluster). Next, in the hospitals selected as per the number of the employed nurses, sampling was randomly performed in all the three shifts.

To observe ethical considerations, the participants were informed of the study objectives and of the voluntary nature of the study. Prior to the study, nurses' informed consent was obtained. Questionnaires were completed by the nurses anonymously, and they were assured of the confidentiality of the information. Furthermore, the authorities of the research centers were informed that if they wished, the results would be available to them. All the questionnaires were filled out in the presence of the researcher for 20 minutes in a quiet room in the studied wards.

After collecting the questionnaires, the response "Never" was assigned a score of 1 , and "In all situations" option was given 5 scores, and the questions were ranked in the relevant fields.

The minimum and maximum possible scores were 40 and 200, respectively, and in order to convert the scores to a grading scale out of 100, the total score was divided by 2 . Finally, the moral intelligence of the studied participants was ranked as follows: 90 - 100 very high, 80 - 89 high, 60 79 moderate, 40 - 59 low, and 20 - 39 very low (11).

To analyze the data, descriptive statistics such as mean, frequency, and percentage and inferential tests such as Mann-Whitney U test and Kruskal-Wallis test were used in SPSS, version 16. The distribution of moral intelligence scores and general scores was not normal based on the Kolmogorov-Smirnov test. P value less than 0.05 was considered statistically significant.

\section{Results}

In this study, 200 nursing staff from 10 selected public hospitals of Guilan province were studied, whose mean age was $34.28 \pm 6.86$ years; $89 \%$ of the nurses were female and $11 \%$ were male. In terms of employment status, most of the studied subjects (40\%) were arbitrary and most of the subjects (20\%) were employed in emergency departments (Table 1).

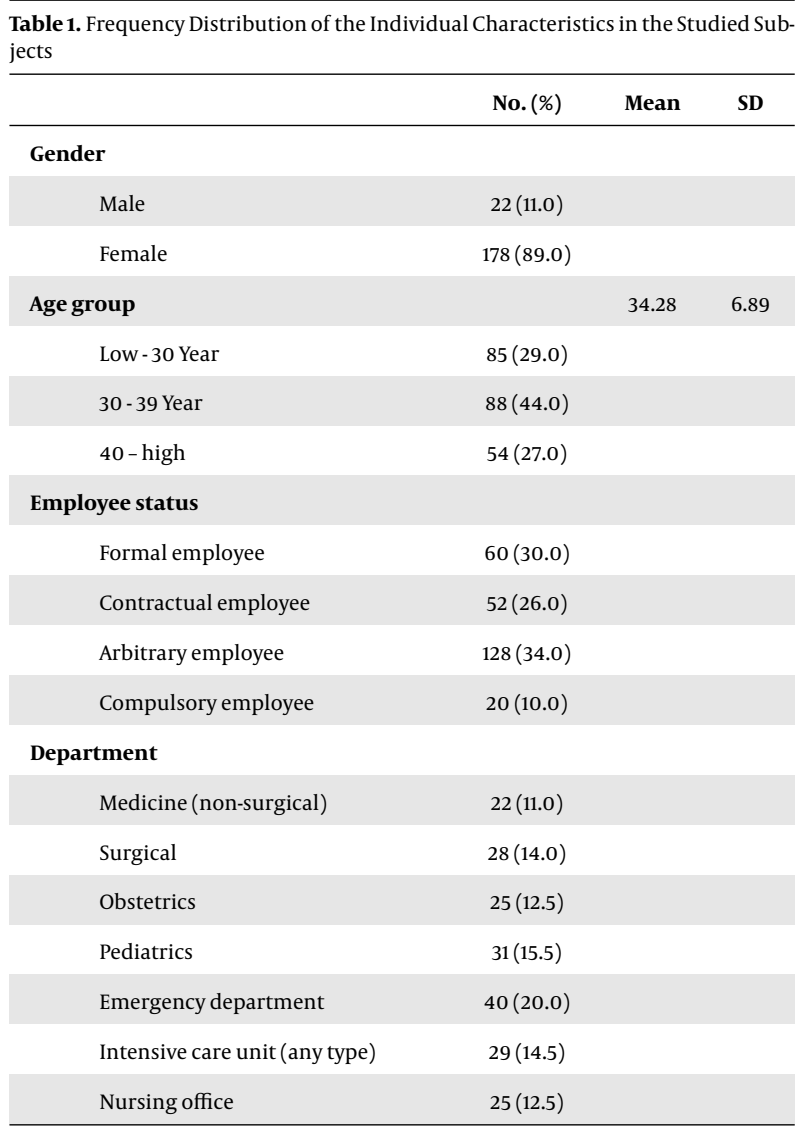

In terms of working experience, the mean duration of employment in the current hospital was years, and the mean duration of employment in the current ward was years. The mean number of working hours per week was hours, and the duration of employment in the nursing care domain was years.

The highest ranking phrases of the moral competency inventory (MCI) in different dimensions were as follows: "I accept that other people will make mistakes" (4.07), "I use my mistakes as an opportunity to improve my performance" (4.04) and "My co-workers would say that my behavior is consistent with my beliefs and values" (4.02). Also, the lowest ranking phrases in the MCI in different dimensions were as follows:" If I believe that my boss is doing something that is not right, I will challenge him or her" (3.01), "I can clearly state principles, values, and beliefs that guide my actions" (3.24), and "My first response when I meet new people is to be genuinely interested in them" 
(3.25).

Based on the findings, the three competencies of "Admitting mistakes and failures" with the mean score of 15.49 \pm 3.09 , "Keeping promises" with the mean score of $15.24 \pm$ 2.31, and "Actively caring about others" with the mean score of $15.16 \pm 2.32$ were considered as the most important competencies of moral intelligence, respectively.

The majority of the respondents (65\%) had moderate moral intelligence, and the least percentage of the subjects (4.5\%) had a low level of moral intelligence (Table 2). Comparison of the four dimensions of moral intelligence showed that the responsibility dimension had the highest score (Table 3).

\begin{tabular}{lc}
\hline Table 2. Frequency Distribution of Moral Intelligence in the Studied Subjects \\
\hline Valid & No. (\%) \\
\hline Very Low & $2(1.0)$ \\
Low & $9(4.5)$ \\
Moderate & $130(65.0)$ \\
High & $48(24.0)$ \\
Very High & $11(5.5)$ \\
Total & $200(100.0)$ \\
\hline
\end{tabular}

The comparative study of moral intelligence in terms of educational level using the Kruskal-Wallis test showed significant differences in the competencies of "Acting consistently with principles, values, and beliefs" ( $\mathrm{P}<0.005)$, "Telling the truth " $(\mathrm{P}<0.044)$, "Standing up for what is right" $(\mathrm{P}<0.004)$, "Keeping promises" $(\mathrm{P}<0.017)$, "Taking responsibility for personal choices" $(\mathrm{P}<0.0001)$, "Embracing responsibility for serving others" $(\mathrm{P}<0.011)$, "Actively caring about others" $(\mathrm{P}<0.016)$, "Ability to let go of one's own mistakes" $(\mathrm{P}<0.018)$, "Ability to let go of others' mistakes" $(\mathrm{P}<0.002)$. Therefore, the mean scores of moral intelligence in nurses with a master's degree in the competencies of "Telling the truth" (16.10 \pm 1.04$)$, "Standing up for what is right" (16.00 \pm 1.77$)$, "Keeping promises" (17.25 \pm 1.75), "Embracing responsibility for serving others" (17.00 $\pm 1.20)$, "Actively caring about others" (17.00 \pm 0.93$)$, "Ability to let go of one's own mistakes" (17.38 \pm 1.30$)$, "Ability to let go of others' mistakes" (17.13 \pm 0.83$)$, and "Acting consistently with principles, values, and beliefs" were higher than other educational levels. The score of "Acting consistently with principles, values, and beliefs" competency was higher in those with associate's degree compared to others.

The comparison of the scores of moral intelligence based on gender by the Mann-Whitney test reflected a significant difference in "Ability to let go of one's own mistakes" $(\mathrm{P}<0.027)$. The mean score of moral intelligence in men (16.14 \pm 1.55$)$ was higher than women.

Comparison of moral intelligence based on age group by Kruskal-Wallis test demonstrated significant differences in "Admitting mistakes and failures" $(\mathrm{P}<0.025)$ and "Embracing responsibility for serving others" $(\mathrm{P}<0.037)$. The moral intelligence score of the 40-year-old age group in these competencies with the mean scores of $15.61 \pm 2.58$ and $15.35 \pm 2.62$ was higher than those of other age groups.

A comparative study of the scores of moral intelligence based on department by the Kruskal-Wallis test showed significant differences in the competencies of "Acting consistently with principles, values and beliefs" $(\mathrm{P}<0.001)$, "Telling the truth" $(\mathrm{P}<0.001)$, "Taking responsibility for personal choices" $(\mathrm{P}<0.015)$, "Embracing responsibility for serving others" $(\mathrm{P}<0.025)$ and "Actively caring about others" $(\mathrm{P}<0.013)$. Thus, the mean scores of moral intelligence in the staff working in pediatric departments in the competencies of "Acting consistently with principles, values and beliefs" (16.10 \pm 1.37$)$, "Telling the truth" (15.84 \pm $1.68)$, and "Actively caring about others" $(16.13 \pm 1.86)$ and the mean scores of nurses working in labor units in the competencies of "Keeping promises" (16.16 \pm 2.30$)$, "Taking responsibility for personal choices" $(15.8 \pm 1.23)$, and "Embracing responsibility for serving others" $(15.76 \pm 2.59)$ were higher than those working in other departments.

Logistic regression model was used for multivariate analysis of the relationship between moral intelligence and demographic variables. In this model, the sub-scores (76) were considered as zero and upper median score was considered as 1, and multiple regression models were implemented using Backward LR method. The results of this model showed that in the analysis of multiple variables (i.e., employment status, department, age, and gender), only department was considered as a factor related to moral intelligence, such that nurses working in emergency $(R=0.007)$, pediatrics $(P=0.001)$, and obstetrics $(P=$ 0.001) departments had higher median scores than nurses working in intensive care units (Table 3).

Odds Ratio $\frac{\text { obestetrics unit }}{\text { intensive care unit }}=8.0895 \%$ CI $: 2.38-27.34$

Odds Ratio $\frac{\text { pediatrics unit }}{\text { intensive care unit }}=6.695 \%$ CI $: 2.12-20.55$

Odds Ratio $\frac{\text { emergency unit }}{\text { intensive care unit }}=4.2595 \%$ CI $: 1.47-12.2$

In other words, the score of moral intelligence was not significant in comparison to the intensive care unit.

\section{Discussion}

Based on our findings, evaluation of the views of the studied participants showed that the highest mean score 


\begin{tabular}{|c|c|c|c|c|c|c|}
\hline Dimensions & Mean & Standard Deviation & Median & Mean Difference & Std. Error & P Value \\
\hline Honestly & 14.71 & 2.07 & 15.25 & 0.223 & 0.048 & 0.000 \\
\hline \multicolumn{7}{|c|}{ A. Acting consistently with principles, values, and beliefs } \\
\hline \multicolumn{7}{|c|}{ B. Telling the truth } \\
\hline \multicolumn{7}{|c|}{ D. Keeping promises } \\
\hline Responsibility & 15.16 & 2.16 & 15.33 & -0.229 & 0.061 & 0.002 \\
\hline \multicolumn{7}{|c|}{ E. Taking responsibility for personal choices } \\
\hline \multicolumn{7}{|c|}{ F. Admitting mistakes and failures } \\
\hline \multicolumn{7}{|c|}{ G. Embracing responsibility for serving others } \\
\hline Forgiveness & 15.14 & 2.15 & 15.00 & -0.222 & 0.060 & 0.003 \\
\hline \multicolumn{7}{|c|}{ H. Actively caring about others } \\
\hline \multicolumn{7}{|c|}{ I. Ability to let go of one's own mistakes } \\
\hline Compassion & 14.70 & 2.13 & 15.00 & 0.238 & 0.102 & 0.211 \\
\hline \multicolumn{7}{|c|}{ J. Ability to let go of others' mistakes } \\
\hline MCI_average & 14.93 & 1.93 & 15.20 & - & - & - \\
\hline
\end{tabular}

Abbreviation: SD, Standard Deviation.

\begin{tabular}{|c|c|c|c|c|c|c|}
\hline & \multirow[t]{2}{*}{ B } & \multirow[t]{2}{*}{ S.E. } & \multirow[t]{2}{*}{ P Value } & \multirow[t]{2}{*}{ Odds Ratio } & \multicolumn{2}{|c|}{ 95\% C.I. For OR } \\
\hline & & & & & Lower & Upper \\
\hline Department & & & 0.004 & & & \\
\hline Medicine (non-surgical) & 0.586 & 0.620 & 0.345 & 1.796 & .532 & 6.057 \\
\hline Surgical & 0.710 & 0.581 & 0.222 & 2.034 & 0.651 & 6.356 \\
\hline Obstetrics & 2.090 & 0.622 & 0.001 & 8.082 & 2.389 & 27.342 \\
\hline Pediatrics & 1.887 & 0.580 & 0.001 & 6.600 & 2.119 & 20.554 \\
\hline Emergency department & 1.447 & 0.539 & 0.007 & 4.252 & 1.478 & 12.231 \\
\hline Nursing office & 0.904 & 0.592 & 0.127 & 2.469 & 0.774 & 7.882 \\
\hline Intensive care unit (any type) & 0 & \multicolumn{2}{|c|}{ Reference Group } & 1 & & \\
\hline Constant & -1.145 & 0.434 & 0.008 & 0.318 & & \\
\hline
\end{tabular}

was related to the competency of "I accept that other people will make mistakes". Basically, the fulfillment of nursing responsibilities is only possible through providing scientific and moral care and proper communication with patients, and from this point of view, moral standards in the performance of nurses are more important and sensitive than other cases (7).

Teaching preventive approaches, training group work, proper planning for treatment interventions, and the development of appropriate therapies for specific patients are effective in reducing medical errors (15). The findings emphasize that letting go of a mistake does not mean justifying or excusing unacceptable behaviors, but it empha- sizes contemplating the importance of that mistake (8).

Moreover, among the terms of the MCI, the phrase "I use my mistakes as an opportunity to improve my performance" had the highest mean score. Improving performance helps with improving and maintaining the function of hospital departments through prioritization, design, and implementation of various methods. Performance improvement should be evaluated persistently and rectified if needed (16). In this context, individual evaluation of errors is one of the best ways to achieve improvement in hospital performance.

The phrase "My co-workers would say that my behavior is consistent with my beliefs and values" is one of other 
terms that gained the highest mean score. Studies have shown that people who know how to use universal human principles in their values, goals and activities and are able to distinguish correct beliefs from false ones and those who have strong moral beliefs and behave faithfully have higher psychological health and are more successful in their occupations (17).

According to the findings, the highest percentage of the participants had moderate moral intelligence. Moral intelligence is one of the dimensions of intelligence that can provide a framework for the proper functioning of human beings and function as a predictor of human behavior (18). People with high moral intelligence try to operate in accordance with moral principles. Moral responsibility plays an important role in providing health care. Nurses with higher moral intelligence can understand patients better and do their activities more seriously and correctly (11).

In previous studies, moral intelligence in most nurses was at an intermediate level, which shows that their moral capabilities should be increased and they should be trained the necessary steps in accordance with their behavior. Improving moral intelligence causes increased attention to the interests of others, improvement of understanding in the workplace, reduction of conflicts, improvement of teamwork, and increased commitment, efficiency, and effectiveness $(8,19)$.

The findings of a study on the importance of different competencies of moral intelligence from nurses' point of view showed that the domain of "Admitting mistakes and failures" is the most important area. Studies have shown that one aspect of sense of responsibility is to confess to mistakes and errors, which involves accepting accountability in circumstances when things do not go right (11). Findings have also shown that nurses take responsibility for their mistakes and errors. Confessing to mistakes and errors shows valor and credibility rather than weakness (5).

We noted that among the dimensions of moral intelligence, the highest mean score was related to responsibility. Research has proved that all activities carried out by individuals follow the principle of causation, which implies that some of these decisions are predictable and some of their consequences are complex and surprising (5). Everyone is responsible for improving the lives of other human beings. Humans live in a world where components are interdependent and individuals must be continuously engaged in serving others (8). A comparative study about moral intelligence scores of nurses in terms of educational level showed that moral intelligence score in those with a master's degree was higher in most domains, which is consistent with other studies conducted in this area (20-22).
In a comparative study of moral intelligence scores based on age, the age group of above 40 years had higher moral intelligence score than other age groups in the domains of admitting mistakes, failures and taking responsibility for personal choices. Moral intelligence seems to change over time and through education. Given the fact that moral intelligence is based on the principles, values, and beliefs of the individual, the more transcendent the values and beliefs of the individuals are, the higher the level of their moral intelligence becomes. This progress will also be achieved by advancing the level of education and age.

Studies have shown that moral development is a progressive process in people's lives, and moral intelligence also increases over time and as people's education increases (11). In this regard, it can be pointed out that moral intelligence is acquired and increments by age, and education can improve the dimensions of moral intelligence in nurses. In fact, advancing age and frequent encounters with various issues and challenges can be effective in distinguishing between the correct and wrong deeds and improve the dimensions of moral intelligence in nurses (19).

The comparative study of moral intelligence scores in terms of gender presented that moral intelligence in men is higher than in women. Therefore, the results of this study are consistent with those of previous studies $(22,23)$. However, other researchers reported that the difference in moral intelligence in women is higher than that of men $(19,24)$. Comparison of nurses' moral intelligence scores based on department showed the moral intelligence scores of nurses working in pediatric and maternity departments were higher in most domains than nurses working in other departments. The high sensitivity of services provided in these departments requires experienced and high-performing nurses.

\subsection{Conclusion}

According to the findings, nurses' moral intelligence was at a desirable level, which indicates the amount of attention devoted by nurses to obtain moral standards and emphasizes the moral nature of the clinical environment. Nursing is a valuable profession that is firmly based upon ethics, and this causes nurses to deal with a plethora of moral issues on a daily basis, which is effective in promoting their moral intelligence. According to our results, factors such as age, gender, department and educational level influence moral intelligence. As such, in addition to the aforementioned factors, other factors related to moral intelligence should be considered by managers and relevant authorities.

In sum, familiarity of hospital staff with the concept of moral intelligence and its different dimensions should 
be promoted and authorities and managers of medical departments should hold special training courses and workshops so as to improve moral intelligence of the staff.

\section{Acknowledgments}

The authors would like to thank all the administrators of nursing services and the respected colleagues working in Guilan hospitals for their sincere cooperation. We wish to thank Islamic Azad University of Rasht for their financial support.

\section{Footnotes}

Authors' Contribution: Seyed Ali Majidi and kouchakzadeh Sobhaneh jointly designed the study and determined the settings. Hamideh Safarmohammadi and Seyed Ali Majidi jointly collected the data and took part in data analysis. Seyed Ali Majidi and ehsan Kazemnezhad Leyli contributed to data analysis and interpretation of the results. Seyed Ali Majidi prepared the draft manuscript. All authors read and approved the final manuscript.

Ethical Considerations: Questionnaires were completed by nurses that were without name, and they were assured that the information would remain confidential. Furthermore, the authorities of the research center in this study were informed that if they wished, the results would be available to them

\section{References}

1. Mercer MP, Hernandez-Boussard T, Mahadevan SV, Strehlow MC. Physician identification and patient satisfaction in the emergency department: are they related? J Emerg Med. 2014;46(5):711-8. doi: 10.1016/j.jemermed.2013.08.036. [PubMed: 24462030].

2. Huang CC, You CS, Tsai MT. A multidimensional analysis of ethical climate, job satisfaction, organizational commitment, and organizational citizenship behaviors. Nurs Ethics. 2012;19(4):513-29. doi: 10.1177/0969733011433923. [PubMed: 22753457].

3. Van Der Zande M, Baart A, Vosman F. Ethical sensitivity in practice: finding tacit moral knowing. J Adv Nurs. 2014;70(1):68-76. doi: 10.1111/jan.12154. [PubMed: 23600949].

4. Liu Y, Wang G. Inpatient satisfaction with nursing care and factors influencing satisfaction in a teaching hospital in China. J Nurs Care Qual. 2007;22(3):266-71. doi: 10.1097/01.NCQ.0000277785.52428.a5. [PubMed: 17563597].

5. Martin DE, Rao A, Sloan LR. Plagiarism, integrity, and workplace deviance: A criterion study. Ethics Behav. 2009;19(1):36-50.

6. LaSala CA. Moral accountability and integrity in nursing practice. Nurs Clin North Am. 2009;44(4):423-34. doi 10.1016/j.cnur.2009.07.006. [PubMed: 19850179].
7. Schluter J, Winch S, Holzhauser K, Henderson A. Nurses' moral sensitivity and hospital ethical climate: a literature review. Nurs Ethics. 2008;15(3):304-21. doi: 10.1177/0969733007088357. [PubMed: 18388166].

8. Lennick D, Kiel F. Moral intelligence 2.0: Enhancing business performance and leadership success in turbulent times. Boston: Pearson Prentice Hall; 2011.

9. Borba M. Building moral intelligence: The seven essential virtues that teach kids to do the right thing. San Francisco: Jossey- Bass; 2002.

10. Borba M. The step by step plan to building moral intelligence, nurturing kid's hearts and souls. San Francisco: National Educator Awards, National Council of Self Steam;2005.

11. Lennick D, Kiel F. Moral competence: Enhancing business performance and leadership success. New Jersey: Wharton School Publishing; 2005.

12. Arshiha MS, Talari KL, Noghani F, Sedghi Goyaghaj N, Taghavi Larijani $\mathrm{T}$. The relationship between moral intelligence and communication skills among nursing students. Iran JMed Ethics Hist Med. 2016;9(3):4454.

13. Holt J, Convey H. Ethical practice in nursing care. Nurs Stand. 2012;27(13):51-6. quiz 58. doi:10.7748/ns2012.11.27.13.51.c9451. [PubMed: 23488373].

14. Martin DE, Austin B. Validation of the moral competency inventory measurement instrument: Content, construct, convergent and discriminant approaches. Manage Res Rev. 2010;33(5):437-51.

15. Carbo AR, Tess AV, Roy C, Weingart SN. Developing a highperformance team training framework for internal medicine residents: the ABC'S of teamwork. J Patient Saf. 2011;7(2):72-6. doi: 10.1097/PTS.ob013e31820dbe02. [PubMed: 21587118].

16. Kocher KE, Shane SA, Venkatesh AK, Aronsky D, Asplin BR, Rathlev NK. Interventions to safeguard system effectiveness during periods of emergency department crowding. Acad Emerg Med. 2011;18(12):1313-7. doi: 10.1111/j.1553-2712.2011.01219.x. [PubMed: 22168196].

17. Cox SS, Bennett RJ, Tripp TM, Aquino K. An empirical test of forgiveness motives' effects on employees' health and well-being. J Occup Health Psychol. 2012;17(3):330-40. doi: 10.1037/a0028314. [PubMed: 22642409].

18. Seider S, Gilbert JK, Novick S, Gomez J. The role of moral and performance character strengths in predicting achievement and conduct among urban middle school students. Teach Coll Rec. 2013;115(8):1-34.

19. Rucinski DA, Bauch PA. Reflective, ethical, and moral constructs in educational leadership preparation: Effects on graduates' practices. JEduc Admin. 2006;44(5):487-508.

20. Pierce B, Sweeney B. The relationship between demographic variables and ethical decision making of trainee accountants. Int J Audit. 2010;14(1):79-99.

21. Hernandez T, McGee R. Ethical attitudes toward taking a bribe: A study of four European countries. Euro Asia J Manage. 2012;22(41):3-28.

22. Goldman A, Tabak N. Perception of ethical climate and its relationship to nurses' demographic characteristics and job satisfaction. Nurs Ethics. 2010;17(2):233-46. doi: 10.1177/0969733009352048. [PubMed: 20185447].

23. Martin NL, Woodward B. Will they or won't they? Exploring ethical judgment, gender, age, geographic region, and behavioral intent. Information Systems Educators Conference. Wilmington. 2011.

24. Piquero NL, Vieraitis LM, Piquero AR, Tibbetts SG, Blankenship M The interplay of gender and ethics in corporate offending decisionmaking. J Contemp Crim Justice. 2013;29(3):385-98. 